\title{
INVESTIGATION OF SPRAYING SPOT AND METALLIZATION PATTERN UNDER CONDITIONS OF MICROPLASMA SPRAYING OF COATINGS OF TITANIUM DIOXIDE
}

\author{
Yu.S. BORISOV, S.G. VOJNAROVICH, A.N. KISLITSA and S.N. KALYUZHNY \\ E.O. Paton Electric Welding Institute, NASU
}

11 Bozhenko Str., 03680, Kiev, Ukraine. E-mail: office@paton.kiev.ua

\begin{abstract}
Analyzed is the gained experience in application of gas-thermal technologies in producing of electroconductive, dielectric and resistive coatings for machine building, instrument-making industry and other industry branches. It is shown that the most challenging method for formation of resistive coatings in manufacture of heating elements is a method of the plasma-arc spraying. It was found that during the process of manufacture of the resistive heating elements of small sizes (for example, for radio electronics) by using the method of traditional plasma-arc spraying the losses of material being sprayed, caused by a geometric factor, are increased. In this connection, to increase the degree of applying of sprayed materials, the technology of microplasma spraying is the mostly challenging. The work is aimed at the study of formation of a spraying spot and a metallization pattern under the conditions of microplasma spraying of the titanium dioxide coating. It was found during investigations that the spraying spot of $\mathrm{TiO}_{2}$ has a form of ellipse with 6.0-9.2 mm sizes of axes, where the smaller axis is directed along the horizontal line, and the larger one - along the vertical line. Ratio of axes is 1.01-1.47 and depends on the spraying mode parameters. Determined are the losses of material being sprayed due to a geometric factor, which were $53 \%$ in spraying of path of $1 \mathrm{~mm}$ width and less than $1 \%$ in spraying the path of $5 \mathrm{~mm}$ width. 19 Ref., 1 Table, 5 Figures.
\end{abstract}

$\boldsymbol{K} \boldsymbol{e} \boldsymbol{y} \boldsymbol{w} \boldsymbol{o r d} \boldsymbol{s}:$ microplasma spraying, titanium dioxide, resistive heating element, metallization pattern

Today, a large experience has been gained in producing of different types of coatings, such as electroconductive, dielectric and resistive ones using the methods of gas thermal spraying (GTS), which are designed for different industry branches (machine building, electrical engineering, instrument-making etc.) [1-3].

The resistive coatings, produced by the GTS methods, represent a great practical interest. Analysis of literature about carried out investigations on application of GTS methods for formation of resistive coatings in electrical engineering confirms many times the challenging future of these technologies [4, 5]. With the development and improvement of the GTS technology during the recent years a method of plasma-arc technology finds the more and more wide application in the production of the resistive coatings [6-9]. In particular, this method was perfect in manufacture of resistive heating elements (RHE) [10-12].

The RHE, manufactured by the method of plasma-arc spraying, are characterized by a significant decrease in temperature in current-carrying layers and increase in service life [13-15].
However, during the process of manufacture of RHE of small sizes for radio electronics using the traditional plasma-arc spraying the additional costs appear, caused by increase in losses of material being sprayed, which are characterized as losses connected with a geometric factor. These losses are predetermined by the fact that the spot diameter of spraying for the traditional plasma-arc spraying is $20-25 \mathrm{~mm}$, that exceeds the path width $(2-5 \mathrm{~mm})$ of the RHE.

To increase the degree of application of the material being sprayed it is rational to apply the technology of a microplasma spraying (MPS) $[16,17]$. This technology will allow producing coatings from different types of materials, reducing greatly the losses of material being sprayed due to a small diameter of a spraying spot (3-5 $\mathrm{mm}$ ), having in this case the minimum thermal effect on the substrate, thus allowing coatings to be sprayed on thin-walled parts without their distortion.

In the present work the formation of the spraying spot and metallization pattern was studied under the conditions of microplasma deposition of titanium dioxide coatings, the losses of material being sprayed, caused by a geometric factor 


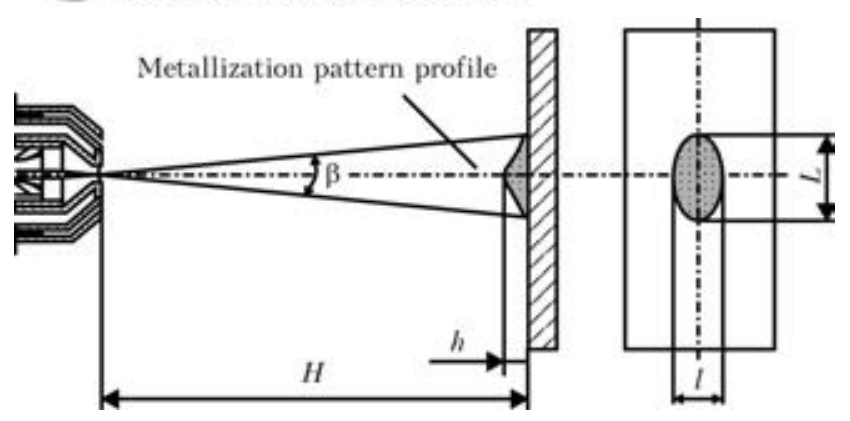

Figure 1. Scheme of metallization pattern investigation

depending on width of path being sprayed, were determined.

To analyze the material losses, connected with a geometric factor, a number of experiments was carried out for determination of parameters of the metallization pattern, which describes the distribution of the coating material mass in the spraying spot. The metallization patterns were obtained during the process of spraying at a fixed plasmatron into a spot on flat specimens of $20 \mathrm{~mm}$ size during $10 \mathrm{~s}$, and then the measurements of vertical (large) $L$ and horizontal (small) axes $l$ of spraying spot, as well as maximum height of the deposited hill $h$ were made (Figure 1).

Using a digital camera the macrofilming of profiles of the metallization pattern was made in the directions normal to its axes (Figure 2).

Then, the processing of image was made for determination of coordinates of the pattern profile. Using MathCad program the metallization pattern was designed according to these coordinates and its describing function was determined, from which the pattern area for larger and smaller axes was calculated. Having data about the sizes of metallization pattern, it is possible to determine such a parameter as an angle of opening of the plasma jet:

$$
\beta=0.5 \operatorname{arctg} \frac{L}{2 H},
$$

where $L$ is the bead width; $H$ is the distance of spraying.

Losses of material, connected with geometric factor, were determined as

$$
L_{\mathrm{g} . \mathrm{f}}=\left(1-S_{\mathrm{x}-\mathrm{x}} / S_{\mathrm{tot}}\right) \cdot 100, \%,
$$

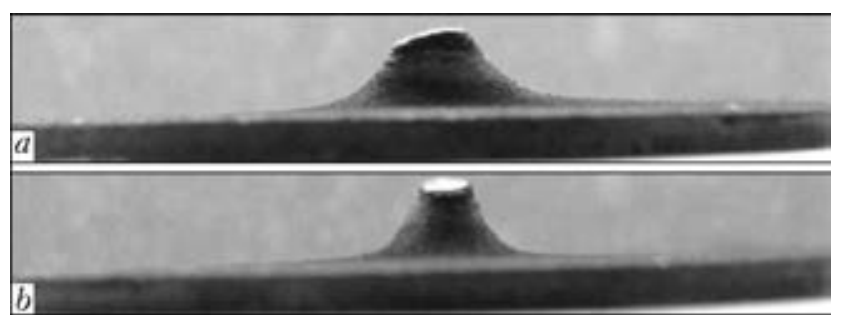

Figure 2. Metallization pattern profiles of $\mathrm{TiO}_{2}$ material: $a$ - large axis; $b-$ small axis

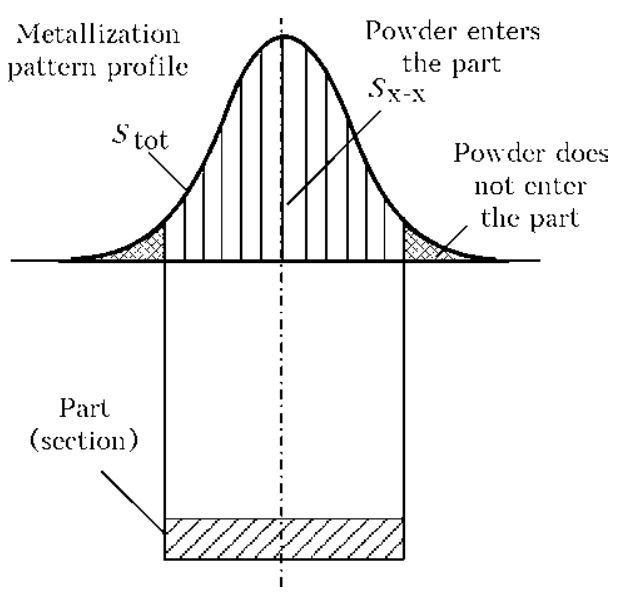

Figure 3. Losses of material due to geometric factor

where $S_{\mathrm{x}-\mathrm{x}}$ is the area of metallization pattern confined by part size; $S_{\text {tot }}$ is the total area of metallization pattern (Figure 3).

The spraying was performed in MPN-004 type installation for MPS. «Metachim» powder of titanium dioxide $\left(\mathrm{TiO}_{2}\right)$ with different sizes of powder of $15-40 \mu \mathrm{m}$ was used as a material for spraying.

The intervals of varying, values of mode parameters being studied and results of the experiment for measurement of geometric parameters of the spraying spot are given in the Table.

It was found during investigations that the spraying spot of $\mathrm{TiO}_{2}$ powder has a form of an ellipse with $6.0-9.2 \mathrm{~mm}$ size of axes, where the smaller axis is directed along the horizontal line and the larger one - along the vertical line. Ratio of axes is 1.01-1.47 and depends on parameters of the spraying mode. Probably, this shape of the spraying spot is caused by the fact that during the powder feeding from batcher MD-004 a gravity force, directed normal to the jet axis, has an effect on its particles. As the powder particles are differed by the size and,

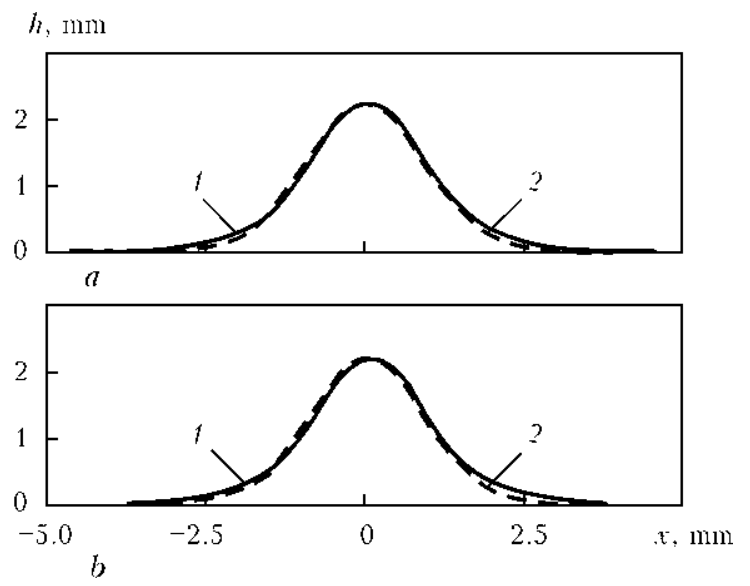

Figure 4. Transverse section of metallization patterns in axes of spray,ing spot: $a-$ section along large axis $y=$ $=2.21 \cdot e^{-0.56 x^{2}} ; \quad b-$ section along small axis $y=$ $=2.21 \cdot e^{-0.6 x^{2}} ; 1-$ diagram of Gauss distribution (calculated); 2 - real metallization pattern profile 

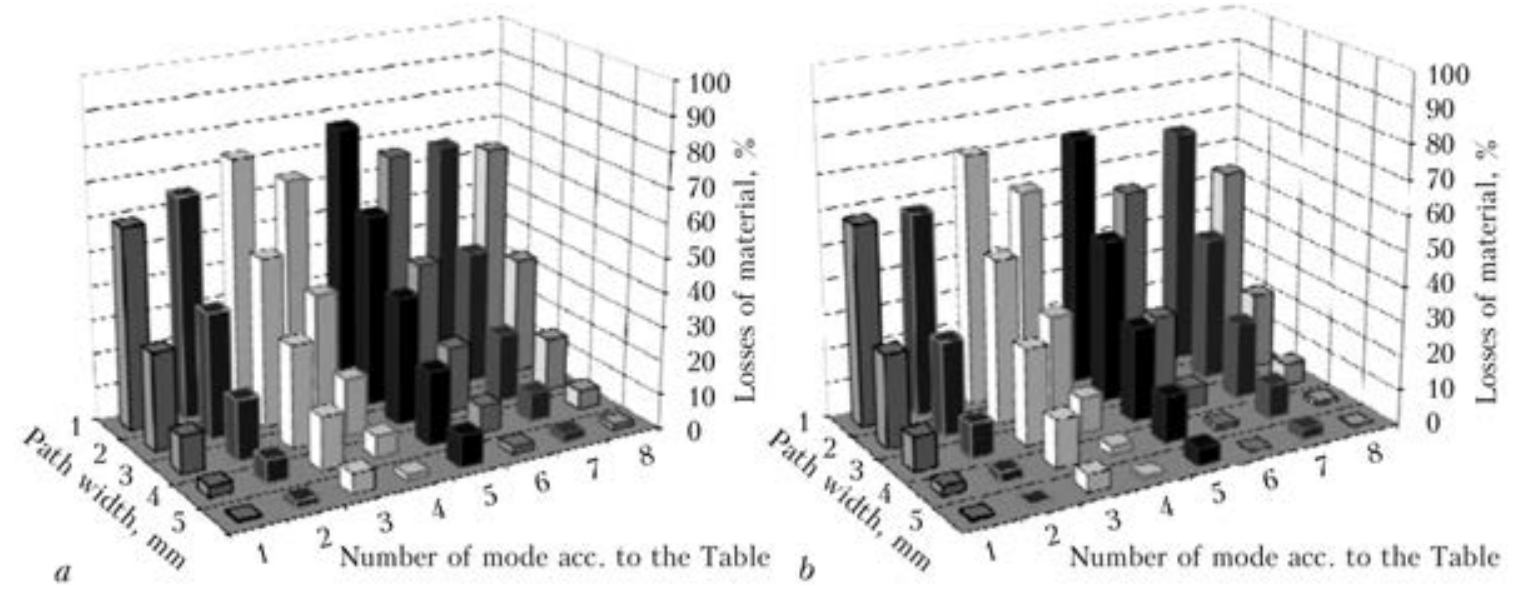

Figure 5. Losses of spraying material connected with geometric factor depending on size of the resistive path: $a-$ for large diagonal; $b$ - for smaller diagonal

Parameters of metallization pattern depending on mode of $\mathrm{TiO}_{2}$ spraying

\begin{tabular}{||c|c|c|c|c|c|c|c||}
\hline $\begin{array}{c}\text { Mode } \\
\text { number }\end{array}$ & $I, \mathrm{~A}$ & $G_{\mathrm{pl}}, \mathrm{l} / \mathrm{min}$ & $H, \mathrm{~mm}$ & $P_{\mathrm{p} . \mathrm{c}}, \mathrm{g} / \mathrm{min}$ & $\begin{array}{c}\text { Height of } \\
\text { metallization } \\
\text { pattern, mm }\end{array}$ & Large axis, mm & Smaller axis, mm \\
\hline 1 & 45 & 120 & 200 & 1.8 & 2.21 & 9.2 & 7.5 \\
\hline 2 & 45 & 120 & 100 & 0.6 & 1.04 & 6.3 & 4.7 \\
\hline 3 & 45 & 60 & 200 & 0.6 & 0.53 & 8.2 & 7.4 \\
\hline 4 & 45 & 60 & 100 & 1.8 & 2.31 & 7.2 & 5.6 \\
\hline 5 & 35 & 20 & 200 & 0.6 & 0.35 & 8.8 & 6.2 \\
\hline 6 & 35 & 120 & 100 & 1.8 & 2.27 & 8.6 & 6.6 \\
\hline 7 & 35 & 60 & 200 & 1.8 & 0.81 & 7.2 & 7.0 \\
\hline 8 & 35 & 60 & 100 & 0.6 & 1.34 & 7.6 & 5.4 \\
\hline
\end{tabular}

consequently, the mass and aerodynamic resistance, they will penetrate into the jet for different depth under the gravity force action. Under these conditions the produced spraying spot will have a shape of ellipse, the larger axis of which is located in the vertical plane, i.e. it coincides with the direction of the gravity force action (see Figure 1). The analysis of nature of the curves showed that the geometry of the metallization pattern at MPS is described rather reliably by the Gauss function [18]:

$$
y=y_{0} e^{-k x^{2}}
$$

where $y_{0}$ is the thickness of coating at the bead axis; $k$ is the coefficient of coating material concentration in the spraying spot.

Using experimental data, obtained as a result of measurements the metallization pattern profiles (measurements were made in large $L$ and small $l$ axes, see Figure 1) were plotted, which coincided with Gauss curves, for different modes of spraying (Figure 4). Coefficient of correlation $K$ was $0.9849-0.9992$. Value of $k$ varied in the range of $0.12-0.97$.

As a result of the carried out calculations according to formula (1) it was found that the angle of opening of the microplasma jet is within the ranges of $2-5.2^{\circ}$. The obtained results correlate with values given in literature for laminar plasma jets [19].

Calculations of losses of material being sprayed, caused by a geometric factor, depending on size of the resistive path, were made for each experiment and are given in the form of histograms (Figure 5).

The analysis of histogram can state that the least losses are provided in applying of the mode 6 (see the Table). This mode is characterized by a minimum value of current and high consumption of plasma gas, that reduces the temperature of the plasma jet, thus decreasing the spraying distance to substrate without risk of its overheating. Decrease in the distance leads in turn to minimizing of the spraying spot. In this case the losses were $53 \%$ in spraying of path of $1 \mathrm{~mm}$ width and less than $1 \%$ in spraying of path of $5 \mathrm{~mm}$.

\section{Conclusions}

1. It was established as a result of study of the process of titanium dioxide coating formation under the MPS conditions that the geometric sizes of the spraying spot depend on the spraying proc- 
ess parameters. The spraying spot has a form of ellipse with $6.0-9.2 \mathrm{~mm}$ sizes of axes at 1.01-1.47 ratio of axes, and metallization pattern is described by the Gauss distribution.

2 . It was shown that it is possible to control the material losses, caused by geometric factor, by selection of MPS modes of resistive paths of $\mathrm{TiO}_{2}$ material. Minimum losses are attained on the conditions of plasmatron operation at the mode 6 , which is characterized by minimum current value and high consumption of plasma gas that reduces the plasma jet temperature and, thus, decreasing the spraying distance to substrate without risk of its overheating with decrease of the spraying spot. This allows providing the minimum losses of material being sprayed to path from 1 up to $5 \mathrm{~mm}$ width that equal to $53 \%$ in spraying of path of $1 \mathrm{~mm}$ width and less than $1 \%$ in spraying of path of $5 \mathrm{~mm}$ width.

1. Vashkevich, F.F., Spalnik, A.Ya., Pluzhko, I.A. (2009) Electrothermal insulation of inductors for internal heating of tube shells. In: Building, materials science, machine building. Dnepropetrovsk: PGSA.

2. Borisov, Yu.S., Kislitsa, A.N. (2002) Microplasma spraying using wire materials. The Paton Welding $J, 3,50-51$.

3. Kovalenko, G.D., Zombzhitsky, A.P. (1980) Specifics of plasma spraying of electric heating coatings with dielectric filler. Fizika $i$ Khimiya Obrab. Materialov, 4, 86-89.

4. Lyasnikov, V.N., Perov, V.V., Lavrova, V.N. (1977) Application of plasma-arc spraying of alundum in manufacturing of cathode-heating assembly-unit. In: Electronic engineering, Series Microwave electronics, Issue 4, 85-87.

5. Baklanov, D.I., Belyajkov, I.N., Virnik, A.M. et al. Method of manufacturing of resistive heating element. Pat. 2066514 RF. Int. Cl. H 05 B 3/12. Publ. 10.09.96.

6. Scheitz, S., Toma, L., Berger, L.-M. et al. (2011) Thermisch gespritzte keramische Schichtheizelemente. Thermal Spray Bull., 4, 88-92.

7. Lyasnikov, V.K., Bogatyrev, G.F. (1978) Plasma spraying of powder materials on parts of electronic devices. In: Review on electronic engineering, Series Technology, industrial engineering and equipment, Issue 4, 62 .

8. Robson, G.J. (1976) Applications of plasma spraying in hard facing. In: Proc. of Public Session and Metals Technology Conf. (Sydney), 6.5.1-6.5.12.

9. Hasui, A. (1975) Procedure of spraying. Moscow: Mashinostroenie.

10. Dostanko, A.P., Vityaz, P.A. (2001) Plasma processes in production of products of electronic engineering, Vol. 3. Minsk: FU AIN FORM.

11. Baranovsky, N.D., Sharonov, E.A., Vannovsky, V.V. (1991) Electrical properties of plasma coatings of plane heating elements. In: Proc. of Conf. on Thermal Spraying in Industry of USSR and Abroad (Leningrad, 27-29 May 1991), 60-61.

12. Griffen, L.A., Dyadechko, A.G. et al. (1990) Heating elements for fittings, produced by thermal spraying method of powders. Poroshk. Metallurgiya, 5, 102-104

13. Ershov, A.A., Urbakh, E.K., Faleev, V.A. et al. (1995) Plasma deposition of resistive layers of strip electrical heater. In: Proc. of Conf. on Physics of Low Temperature Plasma (Petrozavodsk), Pt 3, 409-411.

14. Anshakov, A.S., Kazanov, A.M., Urbakh, E.K. (1998) Creation of low temperature heater by method of plasma spraying. Fizika $i$ Khimiya Obrab. Materialov, 3, 56-61.

15. Smyth, R.T. (1973) Thermal spraying of fine powders. In: Proc. of 7 th Int. Metal Spraying Conf. (London, 1973), 89-95.

16. Borisov, Yu.S., Pereverzev, Yu.N., Bobrik, V.G. et al. (1999) Deposition of narrow-band coatings by method of microplasma spraying. Avtomatich. Svar$k a, 6,53-55$.

17. Kislitsa, A.N., Kuzmich-Yanchuk, E.K., Kislitsa, N.Yu. (2009) Producing of narrow bands by microplasma spraying method from $\mathrm{Ni}-\mathrm{Cr}$ wire. In: Abstr. of All-Ukr. Sci.-Techn. Conf. of Young Scientists and Specialists on Welding and Related Technologies (Kiev, 27-29 May, 2009), 94.

18. Vojnarovich, S.G. (2012) Investigation of shape and size of spraying spot and pattern of metallization under conditions of microplasma spraying of coatings from hydroxyapatite. Vestnik NUK, 3, 81-84.

19. Antsiferov, V.N., Bobrov, G.V., Druzhinin, L.K. (1987) Powder metallurgy and spraying of coatings. Ed. by B.S. Mitin. Moscow: Metallurgiya.

Received 21.10.2014 